EXPERIMENTAL STUDY

\title{
Phosphoinositide 3-kinase inhibits megalin-mediated transcytosis of thyroglobulin across thyroid epithelial cells at a post-sorting level
}

\author{
Michele Marinò ${ }^{1,2}$, Luca Chiovato ${ }^{1}$, Simonetta Lisi $^{1}$, Aldo Pinchera ${ }^{1}$ and Robert T McCluskey ${ }^{2}$ \\ ${ }^{1}$ Department of Endocrinology, University of Pisa, Via Paradisa 2, 56124, Pisa, Italy and ${ }^{2}$ Pathology Research Laboratory, \\ Massachusetts General Hospital, Harvard Medical School, 149 13th Street, Charlestown, Massachusetts, USA \\ (Correspondence should be addressed to Michele Marinò, Department of Endocrinology, University of Pisa, Via Paradisa 2, 56124, Pisa, Italy; \\ Email: m.marino@endoc.med.unipi.it)
}

\begin{abstract}
Background: Phosphoinositide 3-kinase (PI3-K) is implicated in various cellular processes involving signaling, including intracellular trafficking. PI3-K has been shown to play a part in both receptorand non-receptor-mediated transcytosis across cultured kidney cells and undifferentiated thyroid cells.

Objective: To investigate the role of PI3-K in transcytosis of thyroglobulin (Tg) across differentiated cultured Fisher rat thyroid cells (FRTL-5 cells) - a process known to be mediated by megalin, a member of the low-density lipoprotein receptor family.

Design: We studied the effect of the microbial product wortmannin, a specific inhibitor of PI3-K, on transcytosis of Tg across FRTL-5 cells.

Methods: Transcytosis experiments were performed using FRTL-5 cells cultured as tight layers on filters in the upper chamber of dual chambered devices, with megalin expression exclusively on the upper cell surface. $\mathrm{Tg}$ was added to the upper chamber and cells were incubated at $37^{\circ} \mathrm{C}$. Transcytosed $\mathrm{Tg}$ was measured in fluids collected from the lower chamber. To study the role of PI3-K, cells were pre-incubated with wortmannin.

Results: Pre-incubation of FRTL-5 cells with wortmannin did not affect Tg binding and uptake, but resulted in a considerable increase in Tg transcytosis (by 40-75\%, depending on the concentration of wortmannin), suggesting that PI3-K exerts an inhibitory effect on $\mathrm{Tg}$ transcytosis. In experiments in which a monoclonal antibody against megalin was used to reduce Tg transcytosis, pre-incubation with wortmannin did not increase Tg transcytosis from its reduced levels, indicating that PI3-K is involved in the megalin-mediated pathway. Wortmannin did not affect the extent of release of tri-iodothyronine from exogenously added Tg by FRTL-5 cells, which was used as a measure of $\mathrm{Tg}$ degradation in the lysosomal pathway, indicating that the effect of PI3-K on transcytosis occurs after diversion of $\mathrm{Tg}$ from the lysosomal pathway.

Conclusions: PI3-K exerts an inhibitory role on megalin-mediated $\mathrm{Tg}$ transcytosis across cultured thyroid cells. PI3-K action takes place at a post-sorting level, after Tg bypassing of the lysosomal pathway.
\end{abstract}

European Journal of Endocrinology 145 477-483

\section{Introduction}

The intracellular trafficking of thyroglobulin ( $\mathrm{Tg}$ ) in secretory and endocytic pathways has been extensively studied in recent years $(1-5)$. Tg is synthesized by thyrocytes and secreted into the colloid, where it is stored in large amounts (4-7). At the cell-colloid interface, tyrosyl residues of Tg are coupled with iodide, with the formation of thyroid hormones within the $\mathrm{Tg}$ molecule. Hormone release requires $\mathrm{Tg}$ endocytosis from the colloid by thyrocytes and transport along the lysosomal pathway, where thyroid hormones are released by proteolytic cleavage (4-7). However, some internalized $\mathrm{Tg}$ molecules escape the lysosomal pathway and are transported intact by transcytosis from the apical to the basolateral membrane of thyroid cells and then are released into the bloodstream (8, 9). Tg transcytosis occurs after binding and uptake of $\mathrm{Tg}$ via megalin (gp330) (10), a member of the lowdensity lipoprotein (LDL) receptor family $(11,12)$ that is expressed on the apical surface of thyroid epithelial cells in a thyroid-stimulating hormone (TSH)dependent manner (10, 13-15). Megalin-mediated transcytosis of $\mathrm{Tg}$ actively competes with mechanisms 
that lead to thyroid hormone release in the lysosomal pathway, as shown both in cultured thyroid cells and in vivo (10). Thus megalin competitors reduce $\mathrm{Tg}$ transcytosis across cultured thyroid cells, whereas they increase the extent of release of tri-iodothyronine $\left(\mathrm{T}_{3}\right)$ from exogenously added $\mathrm{Tg}$ (10). Furthermore, in rats treated with aminotriazole, in which megalin expression on the apical surface of thyrocytes is markedly increased, there is massive endocytosis of $\mathrm{Tg}$ from the colloid, with increased $\mathrm{Tg}$ concentrations and reduced T3 concentrations in the serum $(10,16)$.

In the present study, we investigated the role of phosphoinositide 3-kinase (PI3-K) in Tg transcytosis via megalin across a Fisher rat thyroid differentiated cell line (FRTL-5 cells) $(17,18)$. PI3-K is a heterodimer composed of two distinct subunits, an $85 \mathrm{kDa}$ regulatory subunit and a $110 \mathrm{kDa}$ catalytic subunit (19-24). PI3-K has phosphoinositide, protein and lipid kinase activity and is involved in several cellular processes, including growth, differentiation and apoptosis (19-24). Many of these PI3-K actions involve signal transduction, which follows protein-receptor interactions on the cell membrane (19-24). In addition, PI3-K participates in various intracellular pathways involving vesicle trafficking (19-24). Hansen et al. (19) have shown that PI3-K is required for efficient apical-to-basolateral and basolateral-to-apical transcytosis of ricin - two non-receptor-mediated processes - across FRT cells, a non-differentiated rat thyroid cell line. Furthermore, they have provided evidence that PI3-K facilitates receptor-mediated transcytosis of dimeric IgA across Madin Darby Canine Kidney cells (MDCK cells) (19). The action of wortmannin on transcytosis was shown to take place at a late stage of the endocytic pathway, after sorting - a step whereby, after their endocytosis, ligands are sorted in early endosomes either toward the lysosomal/degradative pathway or toward the recycling/transcytosis pathway (19). To investigate the role of PI3-K in Tg transcytosis we used a specific PI3-K inhibitor, the microbial product wortmannin $(19,25,26)$. The experiments unexpectedly provided evidence for a novel function of PI3-K, namely inhibition of $\mathrm{Tg}$ transcytosis at a post-sorting level.

\section{Materials and methods}

\section{Materials}

Tg was purified from frozen rat thyroids by ammonium sulfate precipitation and column fractionation, as described elsewhere $(10,27,28)$. Tg preparations were analyzed by western blotting, under both nonreducing and reducing conditions, using a rabbit antihuman $\mathrm{Tg}$ antibody cross-reactive with $\mathrm{Tg}$ from other species (Axle-Westbury, New York, NY, USA). Under non-reducing conditions, two bands of approximately equal intensity were seen at about 660 and $330 \mathrm{kDa}$.
The $660 \mathrm{kDa}$ band corresponded to covalently linked Tg dimers. Size exclusion gel chromatography showed that almost all $(\sim 95 \%)$ of the $330 \mathrm{kDa}$ band represented monomers derived from non-covalently associated $\mathrm{Tg}$ dimers that had been dissociated by SDSPAGE, with a small fraction $(\sim 5 \%)$ of free $\mathrm{Tg}$ monomers. Under reducing conditions, two bands, one slower (S) and one faster (F), were seen, as described previously $(29,30)$. Other Tg products, with lower molecular masses, were negligible.

Heparin (Sigma, St Louis, MO, USA) was used because it effectively releases megalin-bound $\mathrm{Tg}$ (15, 28) and because rat $\mathrm{Tg}$ is a heparin binding protein $(15,27,28)$. Wortmannin and cytochalasin D were obtained from Sigma.

A mouse monoclonal antibody, designated $1 \mathrm{H} 2$, which reacts with megalin ectodomain epitopes in the second cluster of ligand binding repeats, was described previously (31). Alkaline phosphatase (ALP)-conjugated goat anti-rabbit IgG was obtained from Bio-rad (Hercules, CA, USA).

\section{Cell cultures}

FRTL-5 cells (CRL 8305; American Type Culture Collection. Rockville, MD, USA) were cultured as described elsewhere $(17,18)$, in Coon's F12 medium containing 5\% fetal calf serum and a mixture of six hormones, including TSH. Although the batch of FRTL-5 cells used in this study has been shown to be tetraploid $(32,33)$, the FRTL-5 cells used here maintained functions of differentiated thyroid cells: they were found to synthesize and secrete intact $\mathrm{Tg}$ $(10,34)$, to produce cAMP in response to TSH to an extent similar to those previously reported $(18,34)$, to express megalin in a TSH-dependent manner (15) and to release thyroid hormone from exogenously administered Tg (10).

\section{Binding and uptake experiments}

FRTL-5 cells were cultured in 96-well plates until 80$100 \%$ confluence was reached, as previously described (15). The mean number of cells used was $5.46 \times 10^{4}$ cells/well with a mean total amount of protein in cell lysates of $5.60 \mu \mathrm{g} /$ well, as assessed using a commercial kit (Bio Rad). The cells were incubated for $1 \mathrm{~h}$ at $37^{\circ} \mathrm{C}$ with unlabeled Tg $(50 \mu \mathrm{g} / \mathrm{ml}$ in Coon's F12 medium, $5 \mathrm{mmol} / \mathrm{l} \mathrm{CaCl}_{2}, 0.5 \mathrm{mmol} / \mathrm{l} \mathrm{MgCl}_{2}, 0.5 \%$ ovalbumin (OVA)), alone, or in the presence of the monoclonal anti-megalin antibody $1 \mathrm{H} 2(200 \mu \mathrm{g} / \mathrm{ml})$ or, as a control, with normal mouse IgG $(200 \mu \mathrm{g} / \mathrm{ml})$. The cells were then washed and incubated for $1 \mathrm{~h}$ at $4{ }^{\circ} \mathrm{C}$ with ice-cold heparin $(100 \mathrm{U} / \mathrm{ml})$, to release cell-bound $\mathrm{Tg}$. The heparin wash was collected and the cells were lysed with water on ice. Tg was 
detected in the heparin wash by ELISA as a measure of cell-bound $\mathrm{Tg}$, whereas internalized $\mathrm{Tg}$ was measured in cell lysates. We previously showed (18) in similar experiments that almost all of the cell-bound $\mathrm{Tg}$ and of the megalin-bound $\mathrm{Tg}$ are released by heparin. We have also shown (15) that there is only minimal contribution of $\mathrm{Tg}$ endogenously synthesized by FRTL- 5 cells to the amount of cell-bound or intracellular Tg measured after incubation with exogenous $\mathrm{Tg}$.

To study the role of PI3-K, before adding Tg, cells were incubated at $37^{\circ} \mathrm{C}$ for $15 \mathrm{~min}$ with wortmannin $(100 \mathrm{nmol} / \mathrm{l})$ or, as a control, with cytochalasin D (100 $\mu \mathrm{mol} / \mathrm{l})$.

\section{Transcytosis assays}

FRTL-5 cells were cultured in high-density large pore $(3 \mu \mathrm{m})$ filters in cell culture inserts (Becton Dickinson, Mountain View, CA, USA) placed in 24 well plates, as previously described $(10,16,34)$. These devices allow polarization of cells and formation of tight junctions, which makes it possible to trace transfer of molecules across the cells, from the upper (insert) to the lower (cell-culture well) chamber. The filters used were made of polyethylene terephthalate and were not coated with any substrates. Cells were used at complete confluence. The mean number of cells at confluence was $5.32 \times 10^{4}$ cells/well and the mean amount of protein in cell lysates was $\sim 5.21 \mu \mathrm{g} /$ well.

Polarization of confluent cells was assessed by immunofluorescence staining for megalin, as previously described (10). The tightness of cell layers was assessed by measuring the paracellular transport of $\left[{ }^{3} \mathrm{H}\right]$ mannitol, as described previously (10). Transport of $\left[{ }^{3} \mathrm{H}\right]$ mannitol in $1 \mathrm{~h}$ across the cells used here was $0.9 \%$ of the amount added to the upper chamber, indicating that there was only minimal paracellular leakage.

In transcytosis experiments, confluent cells on filters were incubated at $37^{\circ} \mathrm{C}$ with unlabeled $\mathrm{Tg}(50 \mu \mathrm{g} / \mathrm{ml})$ in Coon's F12 medium, $5 \mathrm{mmol} / \mathrm{l} \mathrm{CaCl} 2,0.5 \mathrm{mmol} / \mathrm{l}$ $\mathrm{MgCl}_{2}, 0.5 \%$ OVA. Tg was added in a volume of $200 \mu \mathrm{l}$ to the upper chamber, and the lower chamber was rinsed with $200 \mu \mathrm{l}$ buffer without $\mathrm{Tg}$. After $1 \mathrm{~h}$, the medium from the lower chamber was collected and $\mathrm{Tg}$ was measured by ELISA. In megalin inhibition experiments, Tg was added to the cells together with the antimegalin antibody $1 \mathrm{H} 2(200 \mu \mathrm{g} / \mathrm{ml})$ or, as a control, with normal mouse IgG $(200 \mu \mathrm{g} / \mathrm{ml})$. To study the role of PI3-K, before the addition of Tg, cells were incubated at $37^{\circ} \mathrm{C}$ for $15 \mathrm{~min}$ with wortmannin ( 100 or $200 \mathrm{nmol} / \mathrm{l}$ ) or, as a control, with cytochalasin D $(100 \mu \mathrm{mol} / \mathrm{l})$.

\section{Thyroid hormone release experiments}

FRTL-5 cells were cultured in 24-well plates until $80-100 \%$ confluence was reached. The mean number of cells used in these experiments was $3.61 \times 10^{5}$ cells/well. The mean amount of protein in cell lysates was $38.5 \mu \mathrm{g} /$ well. Cells were incubated at $37{ }^{\circ} \mathrm{C}$ with $200 \mu \mathrm{g} / \mathrm{ml}$ of unlabeled $\mathrm{Tg}$, in Coon's F12 medium containing $5 \mathrm{mmol} / \mathrm{l} \mathrm{CaCl}_{2}, 0.5 \mathrm{mmol} / \mathrm{l} \mathrm{MgCl}_{2}$ and $0.5 \%$ OVA. After $1 \mathrm{~h}$, the medium was collected and $\mathrm{T}_{3}$ was measured by chemiluminescence, at the Massachusetts General Hospital Chemistry Laboratory. Values were normalized for the total amount of protein in the cell lysates. In certain experiments, Tg was added to the cells together with $1 \mathrm{H} 2(200 \mu \mathrm{g} / \mathrm{ml})$, or, as controls, with normal mouse $\operatorname{IgG}(200 \mu \mathrm{g} / \mathrm{ml})$. To study the role of PI3-K, before the addition of Tg, cells were incubated at $37^{\circ} \mathrm{C}$ for $15 \mathrm{~min}$ with wortmannin $(100 \mathrm{nmol} / \mathrm{l})$ or, as a control, with cytochalasin D $(100 \mu \mathrm{mol} / \mathrm{l})$.

\section{ELISAs}

Ninety-six-well microtiter plates were coated with the samples to be tested for $\mathrm{Tg}$ and incubated with the rabbit anti-Tg antibody (1:500), followed by ALP-conjugated goat anti-rabbit IgG (1:3000) and p-nitrophenylphosphate (Sigma). Absorbance at $405 \mathrm{~nm}$ was determined with an E1-311 ELISA microplate reader. The amount of $\mathrm{Tg}$ was estimated using a standard curve obtained by coating the wells with 1-1000 ng purified Tg.

\section{Results}

\section{The PI3-K inhibitor wortmannin increases Tg transcytosis across FRTL-5 cells}

To study the role of PI3-K in Tg transcytosis we used wortmannin, a specific inhibitor of both phosphoinositide protein and kinase activity of PI3-K $(19,25,26)$. After the incubation of FRTL-5 cells for $15 \mathrm{~min}$ at $37{ }^{\circ} \mathrm{C}$ with wortmannin, we did not detect signs of toxic effects to the cells examined by conventional microscopy at intervals up to $24 \mathrm{~h}$.

To study transcytosis of $\mathrm{Tg}$, we used FRTL- 5 cells cultured on permeable filters in dual chambered devices. As described previously (10), under these culture conditions FRTL-5 cells present features of polarity, including megalin expression exclusively on the upper surface of the cell layer, and form tight junctions, which prevent paracellular leakage of $\mathrm{Tg}(10)$.

In confirmation of our previous results $(10,16)$, we found that, after the addition of $\mathrm{Tg}$ to the upper chamber containing FRTL-5 cells on filters and incubation for $1 \mathrm{~h}$ at $37^{\circ} \mathrm{C}$, intact $330 \mathrm{kDa} \mathrm{Tg}$ was present in fluids collected from the lower chamber by western blotting (data not shown). As shown in Fig. 1, $\mathrm{Tg}$ was also found by ELISA in the buffer collected from the lower chamber. The amount of $\mathrm{Tg}$ found in the lower chamber after incubation with buffer lacking $\mathrm{Tg}$ was minimal, indicating that there was no appreciable contribution of endogenously produced $\mathrm{Tg}$ to the amount found in the lower chamber (not shown). 


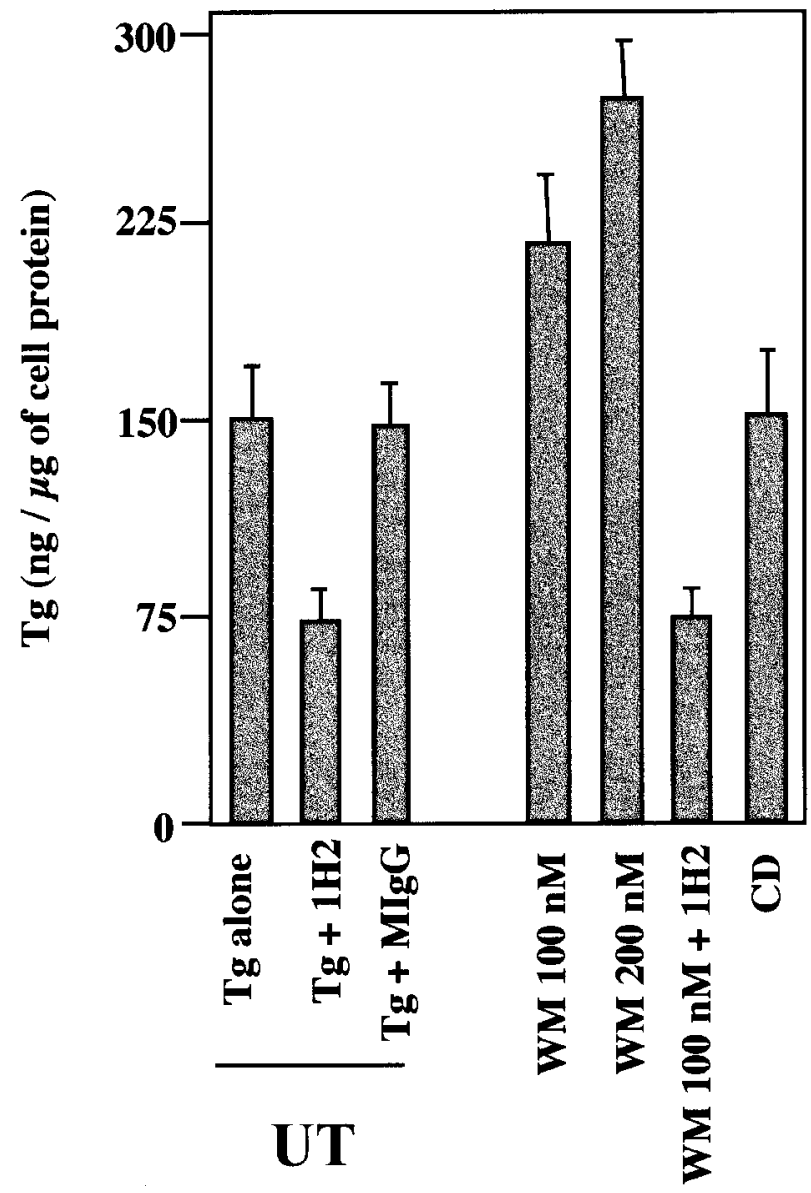

Figure 1 Effect of wortmannin (WM) on Tg transcytosis by FRTL-5 cells. Cells were cultured as polarized layers on filters in cell culture inserts. Cells, either untreated (UT) or treated for $15 \mathrm{~min}$ at $37^{\circ} \mathrm{C}$ with wortmannin or cytochalasin D (CD), were incubated at $37^{\circ} \mathrm{C}$ with unlabeled $\operatorname{Tg}(50 \mu \mathrm{g} / \mathrm{ml})$. Tg was added to the upper chamber, either alone or in the presence of the monoclonal anti-megalin antibody $1 \mathrm{H} 2$ or, as a control, of normal mouse $\operatorname{lgG}$ (MlgG). After $1 \mathrm{~h}$, the medium from the lower chamber was collected and Tg was measured by ELISA. Values were normalized for the total amount of protein in the cell lysates. Results are expressed as mean \pm S.E. obtained in three experiments.

When FRTL-5 cells were pre-incubated with wortmannin, the amount of $\mathrm{Tg}$ found in the lower chamber was increased by $\sim 40 \%$ at a wortmannin concentration of $100 \mathrm{nmol} / \mathrm{l}$ and by $\sim 75 \%$ at a wortmannin concentration of $200 \mathrm{nmol} / \mathrm{l}$ (Fig. 1). No effect on Tg transcytosis was produced by pre-incubation of FRTL-5 cells with cytochalasin D, used as a negative control. When FRTL-5 cells were incubated with $\mathrm{Tg}$ plus $1 \mathrm{H} 2$, a monoclonal anti-megalin antibody, $\mathrm{Tg}$ transcytosis was markedly reduced (Fig. 1), as described previously (10, 34). However, pre-incubation with wortmannin did not alter the degree of reduction of $\mathrm{Tg}$ transcytosis produced by $1 \mathrm{H} 2$ (Fig. 1), indicating that PI3-K is involved in the megalin-mediated pathway.

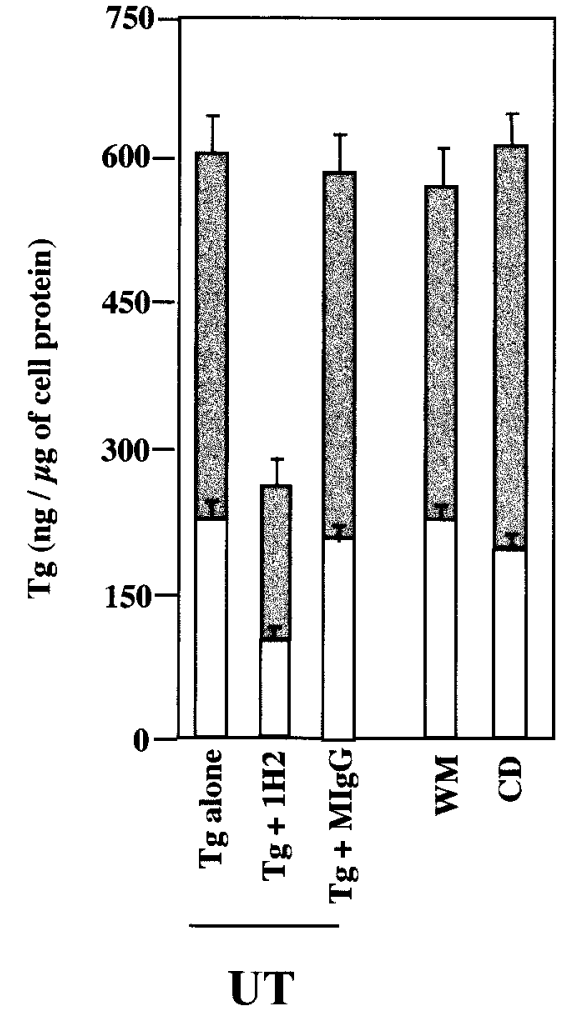

Figure 2 Lack of effects of wortmannin (WM) on Tg binding and uptake by FRTL- 5 cells. Cells, either untreated (UT) or treated for 15 min at $37^{\circ} \mathrm{C}$ with wortmannin or cytochalasin $\mathrm{D}(\mathrm{CD})$, were incubated at $37^{\circ} \mathrm{C}$ with unlabeled rat $\mathrm{Tg}(50 \mu \mathrm{g} / \mathrm{ml})$ for $1 \mathrm{~h}$. In untreated cells, $\mathrm{Tg}$ was added alone or in the presence of the monoclonal anti-megalin antibody $1 \mathrm{H} 2$ or, as a control, of normal mouse IgG (MlgG). After heparin treatment, to release cell-surfacebound $\mathrm{Tg}$, cell lysates were prepared. Bound $\mathrm{Tg}$ was measured by ELISA in the heparin wash and internalized $\mathrm{Tg}$ was measured in the cell lysates. Values were normalized for the total amount of protein in the cell lysates. Results are expressed as mean \pm S.E. obtained in three experiments.

\section{Wortmannin acts at a post-endocytic stage}

As shown in Fig. 2, pre-treatment with wortmannin had no effect on Tg binding and uptake by FRTL-5 cells, indicating that wortmannin affects $\mathrm{Tg}$ transcytosis at a post-endocytic level. In confirmation of previous findings (15), co-incubation with the monoclonal antimegalin antibody $1 \mathrm{H} 2$ reduced both $\mathrm{Tg}$ binding and $\mathrm{Tg}$ uptake by approximately $60 \%$, whereas normal mouse IgG, used as a negative control, did not affect $\mathrm{Tg}$ binding and uptake by FRTL- 5 cells.

\section{The effect of wortmannin occurs after targeting of endocytosed $\mathrm{Tg}$ away from the lysosomal pathway and toward transcytosis}

Megalin-mediated transcytosis of $\mathrm{Tg}$ implies diversion of $\mathrm{Tg}$ from the lysosomal pathway, thereby reducing the 
extent of thyroid hormone release $(10,16)$. To investigate whether PI3-K affects Tg transcytosis before or after sorting of $\mathrm{Tg}$ molecules to the transcytotic or lysosomal pathways, we studied the effect of wortmannin on the release of $\mathrm{T}_{3}$ from exogenously added $\mathrm{Tg}$ by FRTL-5 cells, used as a measure of Tg lysosomal degradation (10). Similar assays for thyroxine $\left(\mathrm{T}_{4}\right)$ were not performed, because they are less sensitive and because, unlike $\mathrm{T}_{3}, \mathrm{~T}_{4}$ can be released by cell-surface proteases in addition to lysosomal degradation (35). Furthermore, $\mathrm{T}_{4}$ can be underestimated as a result of its conversion to $\mathrm{T}_{3}$ by type 1 thyroid deiodinase.

In confirmation of our previous findings (10), after incubation of FRTL- 5 cells with unlabeled $\mathrm{Tg}$ at $37{ }^{\circ} \mathrm{C}$ we detected $\mathrm{T}_{3}$ in the medium and the amount of $\mathrm{T}_{3}$ released was increased by co-incubation of $\mathrm{Tg}$ with the monoclonal anti-megalin antibody $1 \mathrm{H} 2$ (Fig. 3). The effect of $1 \mathrm{H} 2$ reflects the suppression of megalinmediated transcytosis, resulting in increased Tg transport along the lysosomal pathway (10). The effect of $1 \mathrm{H} 2$ on the release of $\mathrm{T}_{3}$ did not parallel the effect of $1 \mathrm{H} 2$ on Tg uptake by FRTL- 5 cells. Thus co-incubation with $1 \mathrm{H} 2$ resulted in a threefold increase in the release of $\mathrm{T}_{3}$ (Fig. 3) and in a $60 \%$ reduction of $\mathrm{Tg}$ uptake (Fig. 2). This phenomenon can be well explained by the fact that one $\mathrm{Tg}$ molecule can contain up to five hormone residues and that the number of hormone molecules released is greater than the number of $\mathrm{Tg}$ molecules internalized and degraded by the cells.

Wortmannin did not affect the release of $\mathrm{T}_{3}$ from exogenous Tg by FRTL-5 cells (Fig. 3), indicating that the effects of wortmannin on transcytosis occur after $\mathrm{Tg}$ has been diverted from the lysosomal pathway after megalin-mediated transcytosis.

\section{Discussion}

In the present study we obtained evidence that PI3-K exerts an inhibitory effect on Tg transcytosis across differentiated cultured thyrocytes (FRTL-5 cells), a process known to be mediated by megalin (10). Transcytosis experiments were carried out using FRTL-5 cells on filters in dual chambered devices, under conditions in which there is no paracellular leakage of molecules. Thus, in previous studies, we have documented that FRTL- 5 cells as used here form tight junctions and exhibit only minimal paracellular leakage even of the relatively small molecule, mannitol (10). Furthermore, the cells exhibit features of polarity, with megalin expression exclusively on the upper (apical) membrane (10). These properties were exhibited by the FRTL- 5 cells used in the present study.

Evidence for an inhibitory role of PI3-K on $\mathrm{Tg}$ transcytosis was provided by experiments in which wortmannin appreciably increased $\mathrm{Tg}$ transcytosis across FRTL-5 cells. At the concentrations used (100 or $200 \mathrm{nmol} / \mathrm{l}$ ), wortmannin is considered to be a highly selective inhibitor of PI3-K, affecting both its

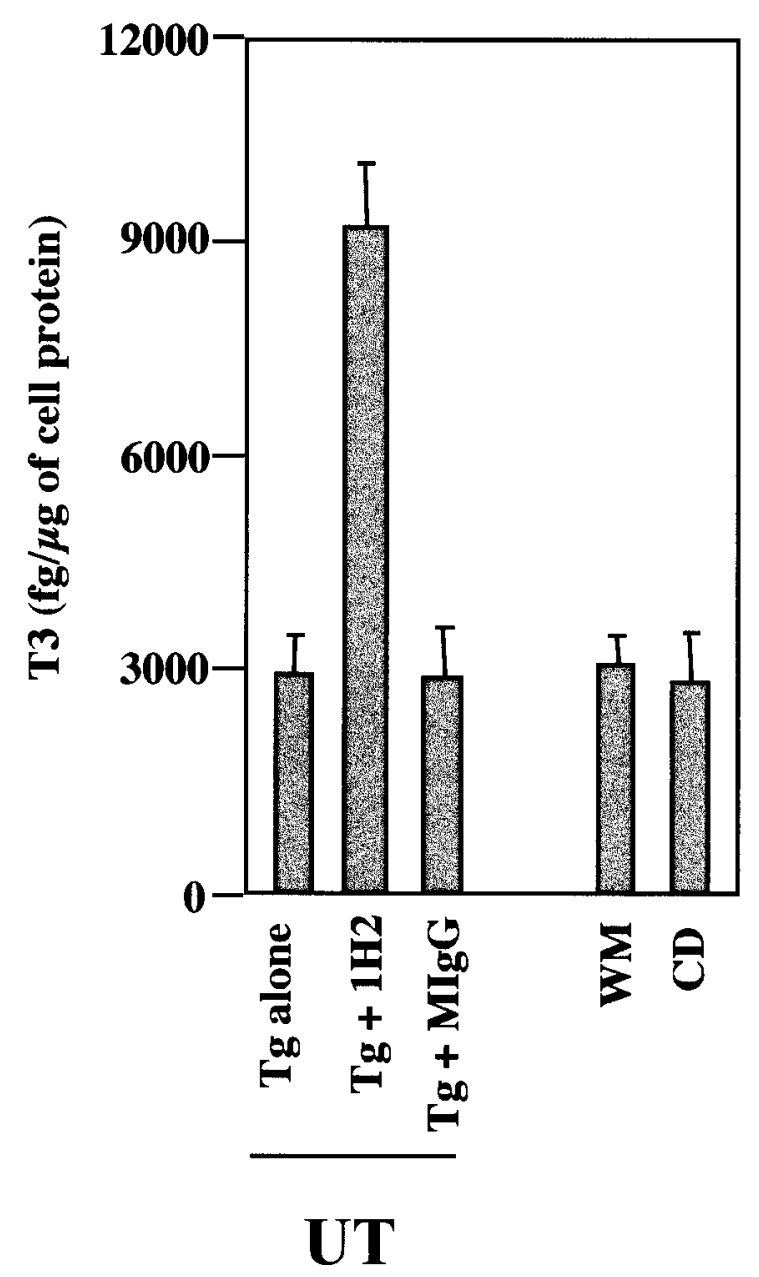

Figure 3 Lack of effect of wortmannin (WM) on the release of $T_{3}$ from exogenous Tg by FRTL- 5 cells. Cells, either untreated (UT) or for treated 15 min at $37^{\circ} \mathrm{C}$ with wortmannin or cytochalasin D (CD), were incubated at $37^{\circ} \mathrm{C}$ with unlabeled rat $\mathrm{Tg}(200 \mu \mathrm{g} / \mathrm{ml})$ for $1 \mathrm{~h}$. Tg was added to the upper chamber either alone, or in the presence of the monoclonal anti-megalin antibody $1 \mathrm{H} 2$ or, as a control, of normal mouse IgG (MlgG). The medium was collected and $T_{3}$ was measured by chemiluminescence. Values were normalized for the total amount of protein in the cell lysates. Results are expressed as mean \pm S.E. obtained in three experiments. $\mathrm{No}_{3}$ was detected in the medium containing $\mathrm{Tg}$ not incubated with the cells.

phosphoinositide and protein kinase activities (19, 25, 26). We found that wortmannin did not affect $\mathrm{Tg}$ binding and uptake by FRTL-5 cells, indicating that PI3-K exerts its inhibitory effects intracellularly.

Because $\mathrm{Tg}$ transcytosis across thyrocytes is a megalin-mediated process (10), it is reasonable to assume that PI3-K acts on the megalin-mediated Tg transcytotic pathway. Two lines of evidence obtained in the present study support this interpretation. Firstly, wortmannin did not affect an intracellular Tg transport pathway previously shown to be independent of megalin (10), namely transport of $\mathrm{Tg}$ to the lysosomal 
pathway, where degradation of $\mathrm{Tg}$ and release of $\mathrm{T}_{3}$ occur. Secondly, and more important, we found that, when megalin-mediated $\mathrm{Tg}$ transcytosis was reduced by an anti-megalin antibody, wortmannin was not able to exert an enhancing effect on $\mathrm{Tg}$ transcytosis.

It is not known how megalin targets $\mathrm{Tg}$ towards transcytosis after its endocytosis at the apical surface of thyrocytes. However, we have recently shown (16) that some of the transcytosed Tg remains complexed with a large portion (secretory component) of the megalin ectodomain through its journey to the basolateral surface. It is likely that signals delivered to megalin-Tg complexes through the cytoplasmic domain of megalin are involved in targeting of $\mathrm{Tg}$ to the transcytotic pathway. In this connection, it is of interest that both rat and human megalin have been shown to contain a potential Src-homology (SH2) binding sequence, conforming to the YXXM consensus recognition sequence for the p85 regulatory subunit of PI3-K $(12,36)$. The interaction of PI3-K with YXXM sequences might lead to activation of second messengers that could affect membrane trafficking (37).

Our results indicate that the enhancing effect of wortmannin on $\mathrm{Tg}$ transcytosis takes place after sorting of $\mathrm{Tg}$ toward the transcytotic pathway. Thus, as mentioned above, wortmannin did not affect $\mathrm{Tg}$ degradation in the lysosomal pathway. The evidence that wortmannin increased $\mathrm{Tg}$ transcytosis at a postsorting level suggests that, under physiological conditions, a certain amount of endocytosed $\mathrm{Tg}$ that avoids the lysosomal pathway is not transcytosed. Because the initial step of transcytosis is common to the recycling pathway, namely entry of endocytosed ligands into recycling/transcytotic endosomes (38), it is possible that the $\mathrm{Tg}$ transcytosed in excess in the presence of wortmannin is normally recycled. Recycling is one of the pathways that $\mathrm{Tg}$ can follow after its endocytosis and it can serve to return immature $\mathrm{Tg}$ molecules into the colloid, where they can be iodinated and become available for endocytosis and hormone release (4). $\mathrm{Tg}$ recycling has been postulated to be mediated by one or more receptors (4). In view of the finding that wortmannin affects the megalin-mediated pathway, it would be interesting to investigate whether megalin also contributes to recycling. On the basis of these considerations it appears that, in thyroid cells, PI3-K may regulate the efflux of internalized $\mathrm{Tg}$ entering the recycling/transcytosis machinery, both by favoring recycling and by inhibiting transcytosis. This effect may prevent a loss of $\mathrm{Tg}$ molecules from the thyroid. Obviously, further studies are needed to investigate this possibility.

As noted earlier, Hansen et al. (19) have shown that PI3-K enhances rather than inhibits transcytosis of ricin (non-receptor-mediated) and of dimeric $\operatorname{IgA}$ (receptor-mediated) across undifferentiated thyroid cells (FRT cells) and MDCK cells. The present findings suggest that the inhibitory effect of PI3-K on $\mathrm{Tg}$ transcytosis may depend on its specific receptor megalin, rather than on constitutive flow of membranes into the transcytosis pathway, as suggested by Hansen et al. (19).

The effect of PI3-K on $\mathrm{Tg}$ transcytosis differs from that of calmodulin: we have recently provided evidence that $\mathrm{Tg}$ transcytosis across FRTL-5 cells is reduced by calmodulin antagonists (34). Furthermore, calmodulin antagonists increased the release of $\mathrm{T}_{3}$ from exogenous $\mathrm{Tg}$ by FRTL-5 cells, indicating that the action of calmodulin on $\mathrm{Tg}$ transcytosis involves diversion of $\mathrm{Tg}$ from the lysosomal pathway, presumably at an early stage after endocytosis (34).

The findings of our previous studies $(10,16,34)$ and the results presented here have provided new insights into the regulation of $\mathrm{Tg}$ transcytosis across thyroid epithelial cells, which is stimulated by calmodulin at a pre-sorting level and inhibited by PI3-K at a later stage of the process. Further studies are clearly needed to elucidate the precise mechanisms by which megalin mediates $\mathrm{Tg}$ transport to the transcytotic pathway.

\section{Acknowledgements}

This work was supported by an American Thyroid Association Research Grant (Michele Marinò), by NIDDK Grant 46301 (Robert T McCluskey) and by Grants from the National Research Council (Consiglio Nazionale Ricerche, Roma, Italy), Target Project Biotechnology and Bioinstrumentation (Grant 91.01219) and Target Project Prevention and Control of Disease Factors (Grant 93.00437), and by EEC Stimulation ActionScience Plan Contract SC1-CT91-0707.

\section{References}

1 Kim PS \& Arvan P. Folding and assembly of newly synthesized thyroglobulin occurs in a pre-Golgi compartment. Journal of Biological Chemistry 1991266 12412-12418.

2 Kim PS, Bole D \& Arvan P. Transient aggregation of nascent thyroglobulin in the endoplasmic reticulum: relationship to the molecular chaperone, BiP. Journal of Cell Biology 1992118 541-549.

3 Kim PS \& Arvan P. Hormonal regulation of thyroglobulin export from the endoplasmic reticulum of cultured thyrocytes. Journal of Biological Chemistry 1993268 4873-4879.

4 Marinò M \& McCluskey RT. Role of thyroglobulin endocytic pathways in the control of thyroid hormone release. American Journal of Physiology 2000279 C1295-C1306.

5 Marinò M, Pinchera A, McCluskey RT \& Chiovato L. Megalin in thyroid physiology and pathology. Thyroid 200111 47-56.

6 Dunn A. Release and secretion of thyroid hormone. In Werner and Ingebar's The Thyroid, a Fundamental and Clinical Text, pp 81-84. Eds LE Braverman \& R Utiger. Philadelphia: Lippincott-Raven, 1996.

7 Rousset B \& Mornex R. The thyroid hormone secretory pathway - current dogmas and alternative hypotheses. Molecular and Cellular Endocrinology 199178 89-93.

8 Herzog V. Transcytosis in thyroid cells. Journal of Cell Biology 198397 607-617.

9 Romagnoli P \& Herzog V. Transcytosis in thyroid follicle cells: regulation and implications for thyroglobulin transport. Experimental Cell Research $1991194202-209$. 
10 Marinò M, Zheng G, Chiovato L, Pinchera A, Brown D, Andrews D et al. Role of megalin (gp330) in transcytosis of thyroglobulin by thyroid cells: a novel function in the control of thyroid hormone release. Journal of Biological Chemistry 2000 275 7125-7138.

11 Raychowdhury R, Niles JL, McCluskey RT \& Smith JA. Autoimmune target in Heymann nephritis is a glycoprotein with homology to the LDL receptor. Science $1989 \mathbf{2 4 4} 1163-1165$.

12 Saito A, Pietromonaco S, Loo AKC \& Farquhar MG. Complete cloning and sequencing of rat gp330/megalin, a distinctive member of the low density lipoprotein receptor gene family. PNAS 199491 9725-9729.

13 Zheng G, Bachinsky DR, Stamenkovic I, Strickland DK, Brown D, Andres G et al. Organ distribution in rats of two members of the low-density lipoprotein receptor gene family, gp330 and LRP/ a2MR, and the receptor-associated protein (RAP). Journal of Histochemistry and Cytochemistry $1994 \mathbf{4 2}$ 531-542.

14 Lundgren S, Carling T, Hjalm G, Juhlin C, Rastad J, Pihlgren U et al. Tissue distribution of human gp330/megalin, a putative $\mathrm{Ca}^{2+}$-sensing protein. Journal of Histochemistry and Cytochemistry 199745 383-392.

15 Marinò M, Zheng G \& McCluskey RT. Megalin (gp330) is an endocytic receptor for thyroglobulin on cultured thyroid cells (FRTL-5 cells). Journal of Biological Chemistry $1999 \quad 27$ 12898-12904.

16 Marinò M, Chiovato L, Latrofa F, Andrews D, Collins BA, Mitsiades $\mathrm{N}$ et al. Circulating thyroglobulin derived from transcytosis is combined with a secretory component of its endocytic receptor megalin. Journal of Clinical Endocrinology and Metabolism $2000853458-3467$.

17 Ambesi-Impiombato FS, Parks LA \& Coon HG. Culture of hormone-dependent functional epithelial cells from rat thyroids. PNAS 198077 3455-3459.

18 Bidey SP, Chiovato L, Day A, Turmaine M, Gould RP, Ekins RP et al. Evaluation of the rat thyroid cell strain FRTL-5 as an in vitro bioassay system for thyrotropin. Journal of Endocrinology 1984 $101269-276$.

19 Hansen SH, Olsson A \& Casanova JE. Wortmannin, an inhibitor of phosphoinositide 3-kinase, inhibits transcytosis in polarized epithelial cells. Journal of Biological Chemistry $1995 \mathbf{2 7 0}$ 28425-28432.

20 Divecha N \& Irvine RF. Phospholipid signaling. Cell 199580 269-278.

21 Kapeller R \& Cantley LC. Phosphatidylinositol 3-kinase. Bioessays 199416 565-576.

22 Panayotou G \& Waterfield MD. The assembly of signaling complexes by receptor tyrosine kinases. Bioessays 199315 $171-172$.

23 Dong Z, Huang C \& Ma WY. PI-3 kinase in signal transduction, cell transformation, and as a target for chemoprevention of cancer. Anticancer Research 199919 3743-3747.

24 Wurmser AE, Gary JD \& Emr SD. Phosphoinositide 3-kinases and their FYVE domain-containing effectors as regulators of vacuolar/lysosomal membrane trafficking pathways. Journal of Biological Chemistry 1999274 9129-9132.
25 Lam K, Carpenter CL, Ruderman NB, Friel JC \& Kelly KL. The phosphatidylinositol 3-kinase serine kinase phosphorylates IRS1. Stimulation by insulin and inhibition by Wortmannin. Journal of Biological Chemistry 1994269 20648-20652.

26 Powis G, Bonjouklian R, Berggren MM, Gallegos A, Abraham R, Ashendel C et al. Wortmannin, a potent and selective inhibitor of phosphatidylinositol-3-kinase. Cancer Research $1994 \mathbf{5 4}$ $2419-2423$.

27 Marinò M, Friedlander JA, McCluskey RT \& Andrews D. Identification of a heparin-binding region of rat thyroglobulin involved in megalin binding. Journal of Biological Chemistry 1999 274 30377-30386.

28 Zheng G, Marinò M, Zhao J \& McCluskey RT. Megalin (gp330): a putative endocytic receptor for thyroglobulin (Tg). Endocrinology $19981391462-1465$.

29 Druetta L, Kroizet K, Bornet H \& Rousset B. Analyses of the molecular forms of serum thyroglobulin from patients with Graves' disease, subacute thyroiditis or differentiated thyroid cancer by velocity sedimentation on sucrose gradient and western blot. European Journal of Endocrinology 1998139 498-507.

30 Gentile F, Palumbo G \& Salvatore G. The origin of the electrophoretic doublet of thyroglobulin. Biochemical and Biophysical Research Communications 1992186 1185-1191.

31 Raychowdhury R, Zheng G, Brown D \& McCluskey RT. Induction of Heymann nephritis with a gp330/megalin fusion protein. American Journal of Pathology 1996148 1613-1623.

32 Tasevski V, Benn D, Peters G, Luttrell B \& Simpson A. The Fischer rat thyroid cell line FRTL-5 exhibits a nondiploid karyotype. Thyroid $1998 \mathbf{8} 623-626$.

33 Zimmermann-Belsing T, Rasmussen AK \& Feldt-Rasmussen U. Lack of thyroglobulin production supports the finding of the FRTL-5 cells with a nondiploid karyotype. Thyroid 19999 519-520.

34 Marinò M \& McCluskey RT. Megalin-mediated transcytosis of thyroglobulin by thyroid cells is a calmodulin-dependent process. Thyroid 200010 461-499.

35 Brix K, Lemansky P \& Herzog V. Evidence for extracellularly acting cathepsins mediating thyroid hormone liberation in thyroid epithelial cells. Endocrinology 1996137 1963-1974.

36 Hjalm G, Murray E, Crumley G, Harazim W, Lundgren S, Onyango I et al. Cloning and sequencing of human gp330, a $\mathrm{Ca}^{2+}$-binding receptor with potential intracellular signalling properties. European Journal of Biochemistry 1996239 132-137.

37 Corvera S, D'Arrigo A \& Stenmark H. Phosphoinositides in membrane traffic. Current Opinion in Cell Biology 199911 460-465.

38 Casanova JE, Wang X, Kumar R, Bhartur SG \& Navarre J, Woodrum JE et al. Association of Rab25 and Rab11a with the apical recycling system of polarized Madin-Darby canine kidney cells. Molecular Biology of the Cell 199910 47-61.

Received 22 February 2001

Accepted 10 May 2001 